\title{
Role of Multiple Liquid Tuned Mass Dampers in Tall Buildings
}

\author{
M. Mahesh ${ }^{1}$ and Dr. N. Murali Krishna ${ }^{2}$ \\ ${ }^{1}$ Junior Engineer, Vishwa Teja Constructions/Attapur, Hyderabad, India \\ Email: maisagallamahesh@gmail.com \\ ${ }^{2}$ Professor, CVR College of Engineering/Civil Engg. Department, Hyderabad, India \\ Email: nmuralikrishna1956@gmail.com
}

\begin{abstract}
High raised buildings with plan asymmetry are highly vulnerable to seismic induced vibrations on account of 1) large amount of base shear, 2) large lateral displacement and 3 ) twist of each story. The asymmetry in the building plan can't be compromised due to the architectural requirements and the buildings utilities. Many techniques are attempted to minimize the base shear, lateral displacement and the twist using methods such as base isolation techniques, tuned massed dampers and the liquid tuned mass dampers. However, though the attempts are found to be fruitful, they are expensive, un acceptable and sometimes not feasible.

In this study the liquid tuned mass dampers are found more suitable and which are modeled making use of the overhead water tanks in buildings. The effect of Multiple Liquid Tuned Mass Dampers on the unsymmetrical buildings is to be studied in the present work. The study is carried-out on L-shape building, T-shape building and $U$-shape and rectangular building of 10, 15 stories height in different seismic zones using E-Tabs. The structural analysis is to be carried using linear time history analysis. It was found that with the increase in number of water head tanks and dampers, the base shear increased, but displacement decreased.
\end{abstract}

Index Terms: Tall structures, tuned mass damper (TMD), Tuned Liquid Mass Damper (TLMD), Base shear, Water tank, Seismic vibrations.

\section{I.INTRODUCTION}

For growing population, the only solution for accommodation remains vertical expansion, when horizontal expansion is limited. High structures pose greater challenges to structural engineer in form of stability and safety. High density tall buildings are vulnerable to lateral forces like wind forces and earthquakes. Lateral displacements at foundation level prove much risk to a buildings stability and pose threat to lives. Hence it becomes a necessity to increase stiffness and improve the structural configuration of buildings to overcome these hurdles.

The introduction of Tuned Mass Damper proved to be highly effective in reduction of base shear and amplitude of vibrations subjected to lateral forces and displacements. These also proved to be economical amongst which the usage of Liquid Tuned Mass Dampers is even more desirable due to their relative advantages. Overhead water tanks then serve as Liquid Tuned Mass Damper, which are economical and serve effectively in control of this distress.

In the present study, the mass of water in the tank plus the mass of the water tank is considered to constitute the total mass of the Tuned Mass Damper. The stiffness of the columns of the water tank would serve as the stiffness of the
Tuned Mass Damper. The structural damping due to the concrete structure constitute the damping of the Tuned Mass Damper. By suitably altering the mass of liquid in the water tank, the sizes of the water tank and the number and size of the column elements supporting the water tank, the mass, the damping and the stiffness of the Tuned Liquid Damper are tuned.

\section{A. Objective of the study}

My predecessor had carried-out studies on the contributions of single liquid tuned mass dampers. In the present work, the studies are extended to investigate the additional contributions due to multiple liquid tuned mass dampers. Having already appreciated the need to introduce multiple liquid tuned mass dampers, the present work is taken-up with following objectives:

1. To suitably choose the size of the water tank, mass of the water tank with water as a ratio of mass of the structure and the number and sizes of the columns supporting the water tank to arrive at an optional configuration of the Liquid Tuned Mass Damper.

2. Proposing either single or multiple numbers of Liquid Tuned Mass Dampers together with their locations and all parameters as described in objective no.1.

3. The overall arrangement should result in the lowest possible base shear and lateral displacement, yet economical in the event of seismic disturbance to the building.

\section{B. Procedure Adopted}

In this current project, ETABS package has been utilized for Response Spectrum method and Time History analysis are on a RCC building subjected to seismic load. A G+10 and $\mathrm{G}+15$ storey building, with and without Liquid Tuned Mass Dampers, located in zone-III and zone-IV of seismic disturbances is considered. L-shaped, T-shaped, U-shaped and rectangular buildings are considered. The studies are repeated by varying the water level in tanks as empty, onethird full, two-third full and full water tank conditions and the locations of the water tanks are altered to result in optimum values of seismic disturbances.

\section{Literature REVIEW}

Chidige Anil Kumar and E Arunakranthi, the aim of the present work is analyzing the feasibility of implementing water tank as passive TMD and finding the optimum level of water which would reduce the peak response of the structure 
subjected to seismic force using SAP2000. The idea of seismic response control of the structures by using TMD's is considered for this study. The frequency of the damper is tuned to a particular structural frequency so that when that frequency is excited, the damper will resonate out of phase with the structural motion and energy is dissipated by the damper inertia force acting on the structure. The building using 1893:2002, it was found that the roof displacements, storey drifts, time period and base shear have been reduced for $2 / 3^{\text {rd }}$ level of water tank compared to other levels. It was concluded by them that if the water level of water in the tank is maintained between half full to two third full there is tendency to mitigate the vibrations of RC frame structures under seismic excitations [1].

Dorothy Reed et al analyzed Time histories of the base shear force and water-surface variations by shaking table tests and compared with a numerical model investigating behavior of tuned liquid dampers (TLD) with the help of laboratory experiment and numerical modelling. It was found that the response frequency of tuned liquid dampers increased as excitation amplitude increased, and the TLD behaved as a hardening spring system. The design frequency damper should be set at the value lower than that of the structure response frequency if it is computed using the linearized water-wave theory by which the actual nonlinear frequency of the damper matched with the structural response. It was found that, even if the damper frequency had been mistuned slightly, the TLD always performed favorably [2].

M. J. Tait, N. Isyumov investigated the performance of unidirectional and directional tuned liquid dampers (TLDs) under random excitation. A series of experiments were carried- out on scale model structure tuned liquid dampers systems for which the results are compared with those of a well-known tuned mass damper. The effective damping was calculated for each test conducted and the efficiency and robustness were subsequently examined. The performance of a mistuned TLD was experimentally investigated to highlight the robustness of these passive dynamic vibration absorbers. A nonlinear numerical model was used to conduct an extensive parametric study on the performance of a tuned liquid damper. It was concluded that a TLD is efficient and robust to reduce dynamic structural motions that occur as a result of random excitation [3].

Mudabbir Imran, Dr. B. K. Raghu Prasad Examined the effectiveness of both single and multiple tuned mass dampers (TMDs) to ease translational vibration when subjected to various earthquake ground accelerations. Making use of ETABS, they had modelled frame with single TMD, frame with multiple TMDs and a shear building with single TMD. Four external loading conditions were considered and the time history analysis was carried out for appropriate ground motion. The variations of displacements in the structural were compared. It was found that the response of the frame structure in terms of displacement reduced with the increase in the mass ratio of the single TMD. It has been observed that a frame structure equipped with MTMD with uniform distribution of mass ratio was more effective in controlling the vibrations of the structure compared to STMD as multiple dampers can weaken different modes. From the frames equipped with MTMD with uniform and non- uniform mass ratios it was seen that MTMD with Non- uniform mass ratio was more efficient than MTMD with uniform mass ratio [4].

\section{Methodology}

The dynamic analysis of the building is carried out using Response Spectrum method Linear Time History method corresponding to seismic Zones-III and IV of seismic activities.

Modelling of structure using TLD is as follows:

1. A three-dimensional model of $\mathrm{G}+10$ and $\mathrm{G}+15$ Stories building Structure is created using ETABS.

2. Created and assigning Material Properties.

3. Created and assigning Section Properties.

4. Response Spectrum and Time History functions are defined for the desired zones considered in the study.

5. Assigning the external and internal wall loads acting on the structure wherever necessary.

6. Assigning the floor finish load and live load acting on slab panels.

7. A water tank is created at the desired location on the top most of the existing building structure.

8. The water tank with desired length, width and height are created and the beam, column and slab properties are assigned.

9. The next step is modelling a Tuned Liquid Damper which is attached to the water tank of the same building.

10. A TLD is modelled in ETABS using a combination of 'Linear link type' and a 'Point spring' attached in series.

11. From the Define $\rightarrow$ Section Properties $\rightarrow$ Link/support properties, add a new link property, add a new link property by selecting the 'Linear link type'. The directional properties $\mathrm{U} 1, \mathrm{U} 2$, and $\mathrm{U} 3$ are selected in which U3 type is fixed.

12. From properties option $\rightarrow$ modify/show all $\rightarrow$ the stiffness and damping values for U1, U2 directions are entered.

13. Mass weight of the TLD (the water) is entered, which is the load acting on the water tank or the weight of water present in the water tank. In this step, the water level is varied to effect the changes in the values of mass weight of TLD and changes are in the stiffness and damping as well.

14. Define $\rightarrow$ Spring properties $\rightarrow$ point springs $\rightarrow$ Add new spring, select the 'User specified/link properties option'.

15. From the 'single joints link at point' dialogue box, add the previous defined link property and the axial direction ' $+Z$ ' selected.

16. Links are drawn using 'draw link' option.

17. The links are connected to the columns in ' $+\mathrm{z}$ ' direction (upward), along which the water tank is standing.

18. The point spring which is defined earlier is assigned to the joints at the base of the water tank by using 'Draw spring' option.

19. The mass of the TLD is assigned towards the free end of the link by selecting the joints of water tank, where springs and links are connected.

20. From the command Assign $\rightarrow$ Joint loads, the load value is assigned in downward or ' $-z$ ' direction. The total load acting on the water tank is divided equally on to the number of columns on which it is standing as shown figure 1 . 


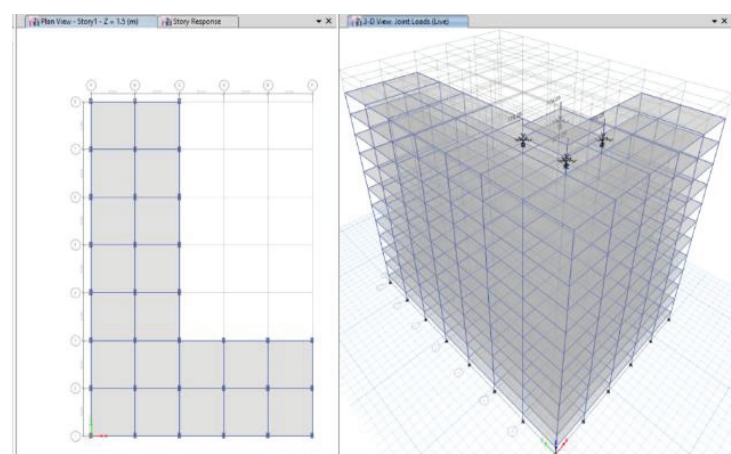

Figure 1. Plan with joint loads in ETABS

The buildings considered for the study are RC ordinary moment resisting space frames of $\mathrm{G}+10$ and $\mathrm{G}+15$ storey located in zone-III and IV of seismic disturbances. The analysis is carried-out on a rectangular shaped building and three different asymmetric shaped buildings of plan shapes L, $\mathrm{T}$ and $\mathrm{U}$. The study is conducted by varying the water level in water tank by considering, 1. Empty water tank, 2. One-third, 3. Two-third's full and 4. Full water tank conditions using ETABS software.

The Plan configurations of $\mathrm{G}+10$, One water tank.

1. Model 1 - L-shaped plan Building (Figure 2),

2. Model 2 - T-shaped plan Building (Figure 3),

3. Model 3 - U-shaped plan Building (Figure 4),

4. Model 4 - Building Rectangular plan (Figure 5),
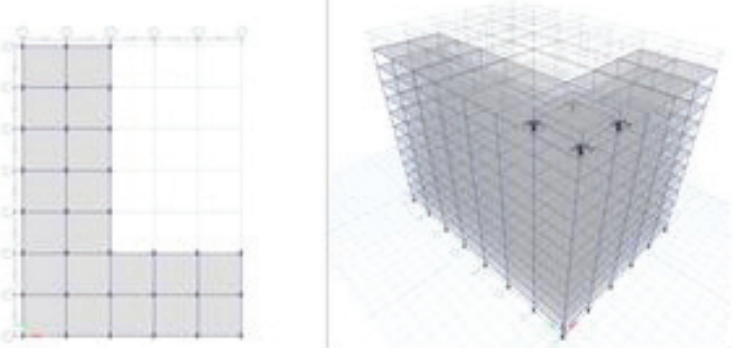

Figure 2. Plan and Isometric view of Model-1 with TLD
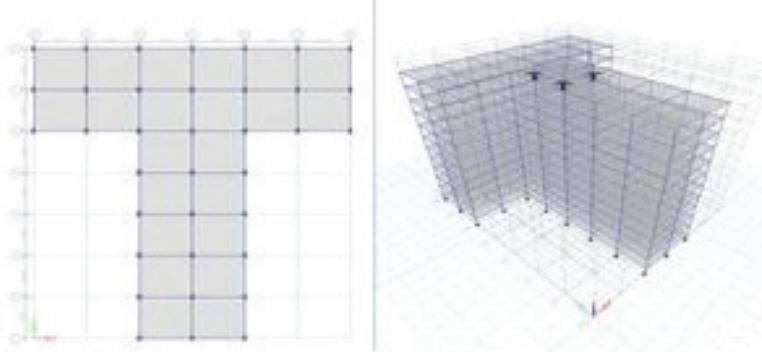

Figure 3. Plan and Isometric view of Model-2 with TLD
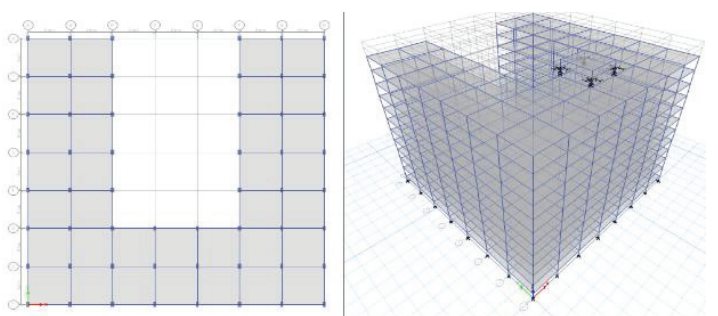

Figure 4. Plan and Isometric view of Model-3 with TLD
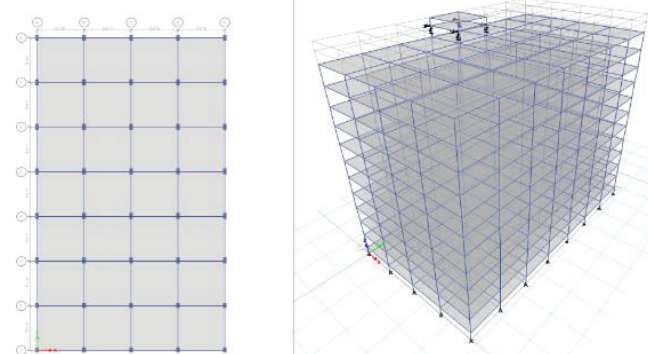

Figure 5. Plan and Isometric view of Model-4 with TLD

The Plan configurations of $\mathrm{G}+10$, Two water tank.

1. Model 5 - L-shaped plan Building (Figure 6),

2. Model 6 - T-shaped plan Building (Figure 7),

3. Model 7 - U-shaped plan Building (Figure 8),

4. Model 8 - Building Rectangular plan (Figure 9),
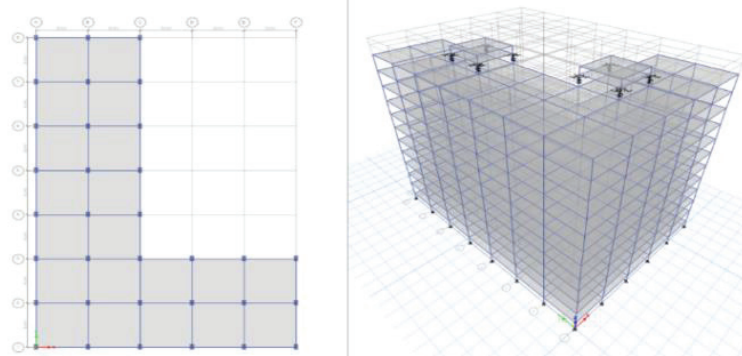

Figure 6. Plan and Isometric view of Model-5 with TLD
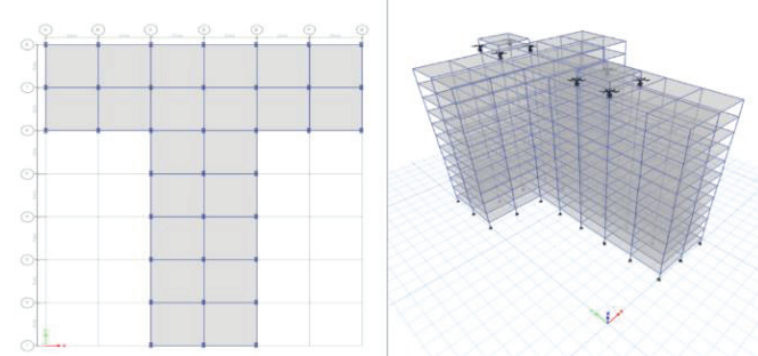

Figure 7. Plan and Isometric view of Model-6 with TLD
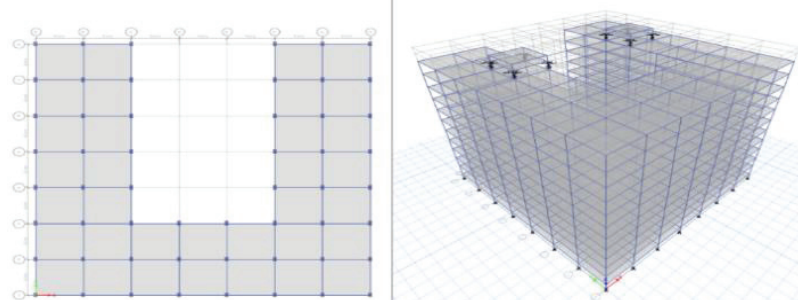

Figure 8. Plan and Isometric view of Model-7 with TLD 

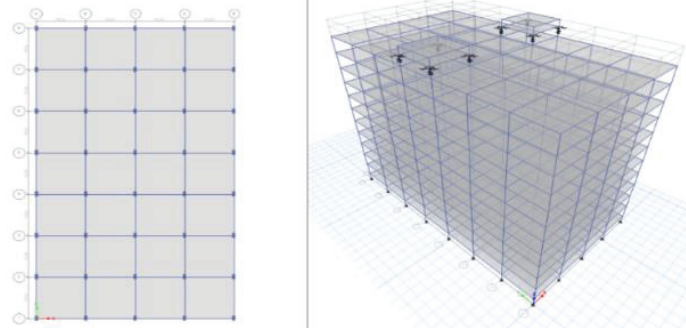

Figure 9. Plan and Isometric view of Model-8 with TLD

The Plan configurations of $\mathrm{G}+10$, Three water tank.

1. Model 9 - L-shaped plan Building (Figure 10),

2. Model 10 - T-shaped plan Building (Figure 11),

3. Model 11 - U-shaped plan Building (Figure 12),

4. Model 12 - Building Rectangular plan (Figure 13),
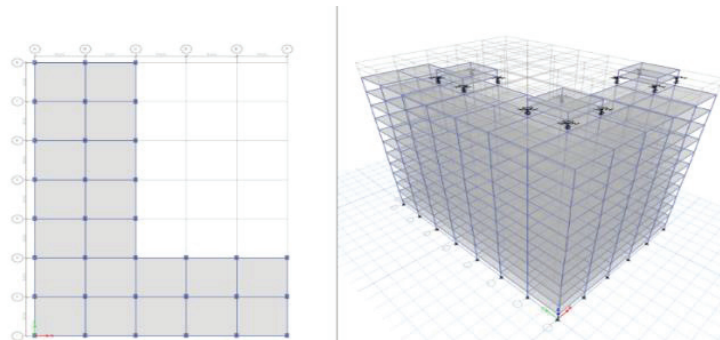

Figure 10. Plan and Isometric view of Model-9 with TLD
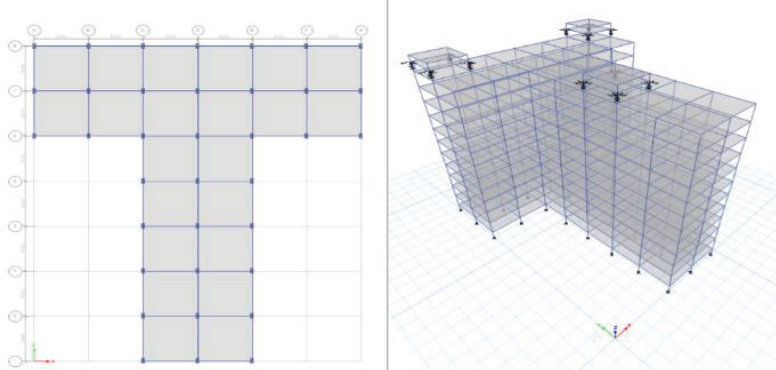

Figure 11. Pan and Isometric view of Model-10 with TLD
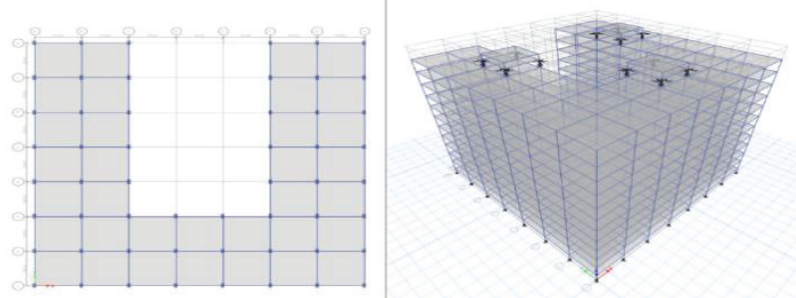

Figure 12. Plan and Isometric view of Model-11 with TLD
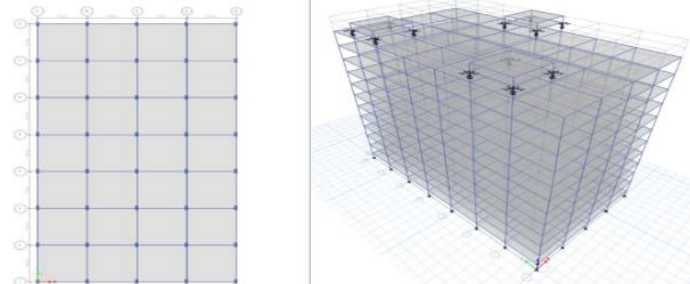

Figure 13. Plan and Isometric view of Model-12 with TLD

The Plan configurations of $\mathrm{G}+15$, One water tank.

1. Model 13 - L-shaped plan Building (Figure 14),

2. Model 14 - T-shaped plan Building (Figure 15),

3. Model 15 - U-shaped plan Building (Figure 16),

4. Model 16 - Building Rectangular plan (Figure 17),
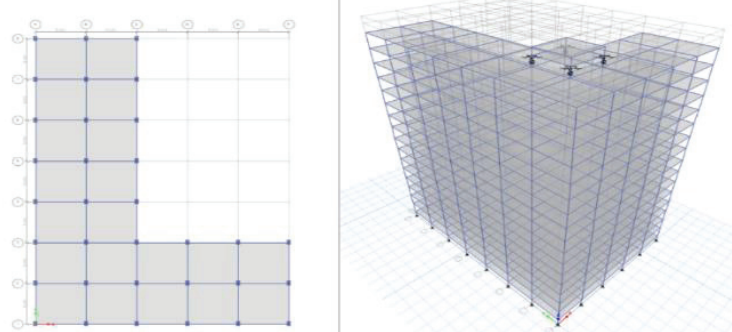

Figure 14. Plan and Isometric view of Model-13 with TLD
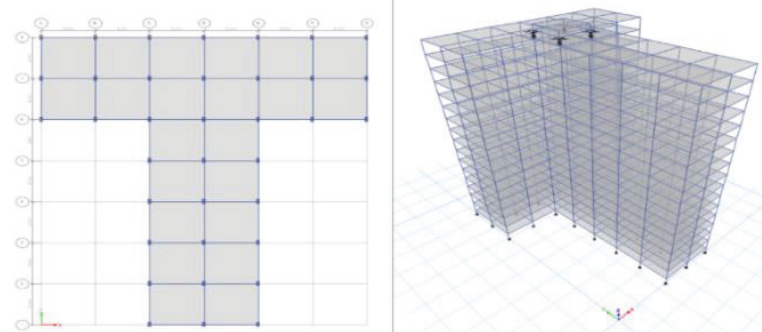

Figure 15. Plan and Isometric view of Model-14 with TLD
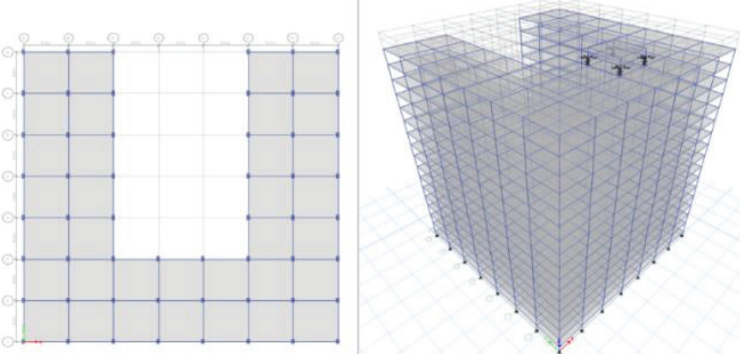

Figure 16. Plan and Isometric view of Model-15 with TLD
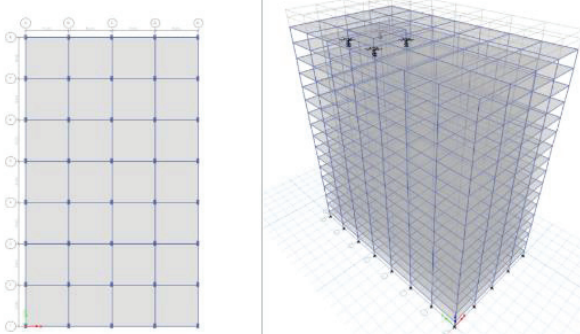

Figure 17. Plan and Isometric view of Model-16 with TLD

The Plan configurations of $\mathrm{G}+15$, Two water tank.

1. Model 17 - L-shaped plan Building (Figure 18),

2. Model 18 - T-shaped plan Building (Figure 19),

3. Model 19 - U-shaped plan Building (Figure 20),

4. Model 20 - Building Rectangular plan (Figure 21),
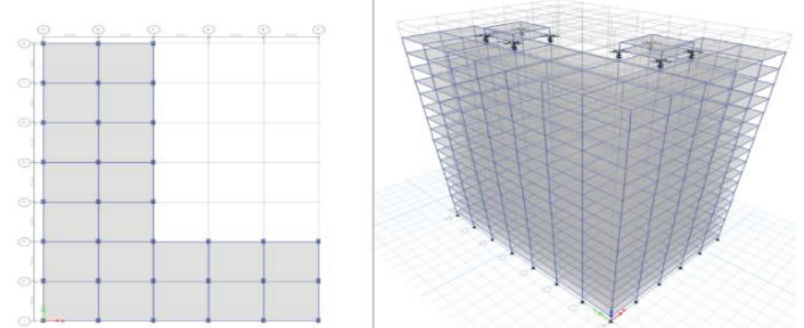

Figure 18. Plan and Isometric view of Model-17 with TLD 

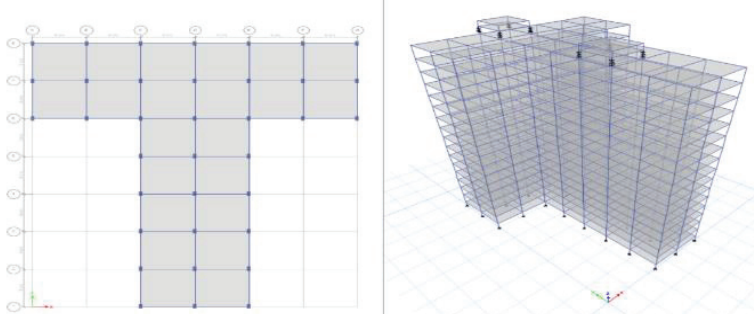

Figure 19. Plan and Isometric view of Model-18 with TLD
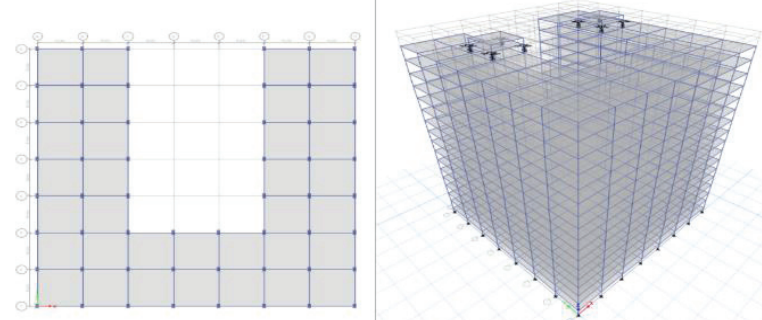

Figure 20. Plan and Isometric view of Model-19 with TLD
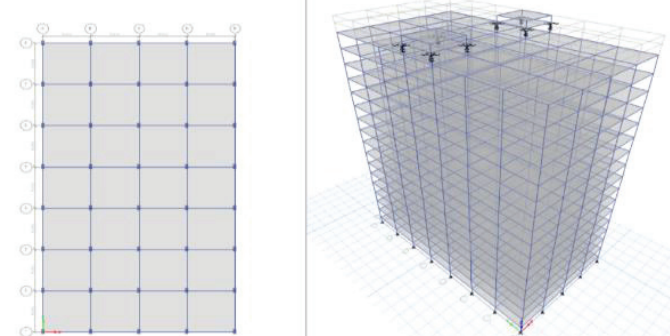

Figure 21. Plan and Isometric view of Model-20 with TLD

The Plan configurations of $\mathrm{G}+15$, Three water tank.

1. Model 21 - L-shaped plan Building (Figure 22),

2. Model 22 - T-shaped plan Building (Figure 23),

3. Model 23 - U-shaped plan Building (Figure 24),

4. Model 24 -Building Rectangular plan (Figure 25),
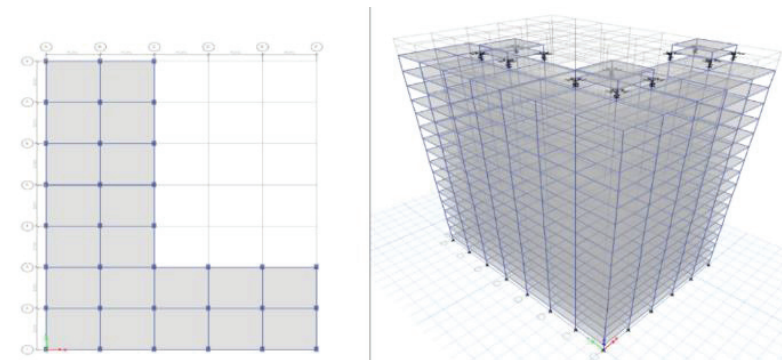

Fig 22. Plan and Isometric view of Model-21 with TLD
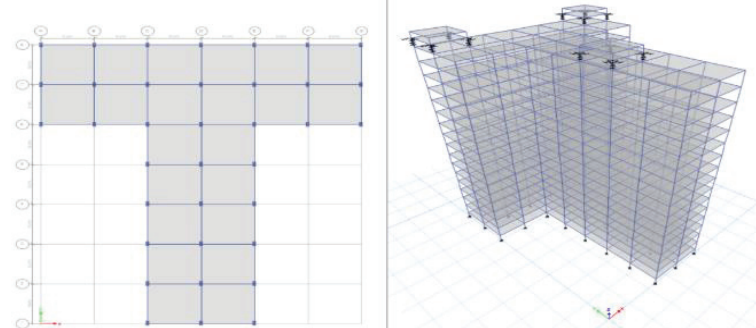

Figure 23. Plan and Isometric view of Model-22 with TLD

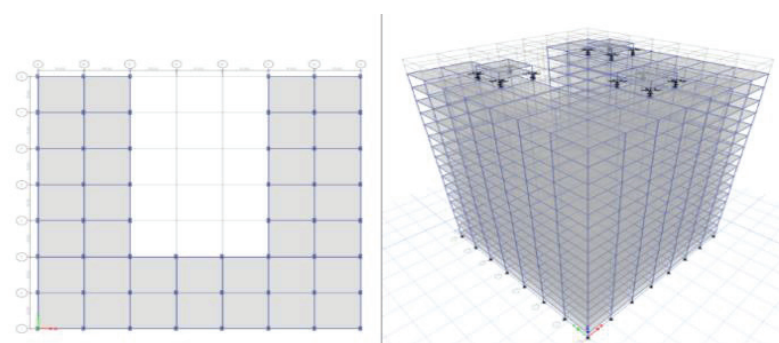

Figure 24. Plan and Isometric view of Model-23 with TLD
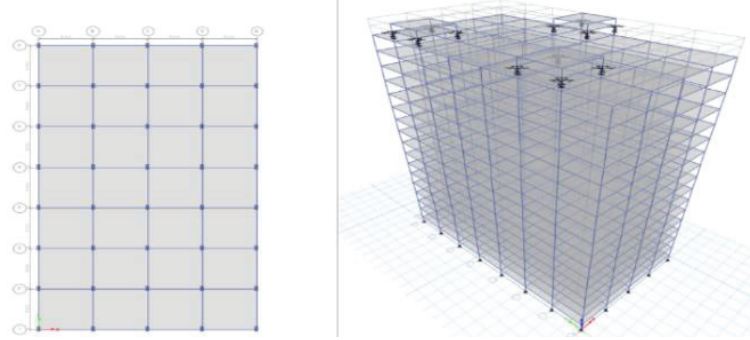

Figure 25. Plan and Isometric view of Model-24 with TLD

\section{Speciemn Calculations}

The preliminary data for the Analysis of the frame in ETABS is considered as per the prevailing construction practice which is presented below.
1. Type of structure
- Moment Resisting Frame
2. Materials
-M30. Fe-500
3. Size of Beams
$-300 \times 450 \mathrm{~mm}$
4. Size of Columns
$-450 \times 750 \mathrm{~mm}$
5. Depth of Slab
$-150 \mathrm{~mm}$
6. External Wall Load
$-11.14 \mathrm{KN} / \mathrm{m}$ (IS 875 Part-1)
7. Internal Wall Load
$-5.57 \mathrm{KN} / \mathrm{m}$ (IS 875 Part-1)
8. Seismic zone factor
-0.16 \& 0.24 (IS893:2016)
9. Response Reduction Factor -5 (IS 1893-2016)

A. Calculations of water tank for Model-L

Total mass of the structure

Water required for single person

No. of persons in each flat

$=70209.18 \mathrm{KN}$

No. of flats in the building

$=135$ liters

Total no of persons

$=5$

$=25$

Water required

$=125$

Water tank height

$=16875$

Volume of tank

$=0.75 \mathrm{~m}$

Area of tank (LxB)

L

$=\mathrm{LxBxH}$

$=22.5 \mathrm{~m}^{2}$

$=6 \mathrm{~m}$

$=6 \mathrm{~m}$

B

$=0.75 \mathrm{~m}$

Total dead load

$=530.82 \mathrm{KN}$

Live Load (Water Required)

Total water tank load

$=165.48 \mathrm{KN}$

$=697.05 \mathrm{KN}$

B. Calculations of the Tuned Liquid Damper for Model-L 
Time period $(\mathrm{Tn})=3.351 \mathrm{sec}$

*Tuning ratio $\left(\mathrm{f}_{\mathrm{opt}}\right)=\frac{1}{1+\gamma}$

*Optimum damping ratio $\left(\xi_{\text {dopt }}\right)=\sqrt{\frac{3 \gamma}{8(1+\gamma)}}$

*Optimum stiffness $\mathrm{K}_{\mathrm{opt}}=\gamma \mathrm{kf}_{\mathrm{opt}}{ }^{2}$

*Optimum Damping $\mathrm{C}_{\mathrm{opt}}=2 \omega \mathrm{m} \xi_{\text {dopt }} \gamma$

The above calculations are listed below in Table-1

TABLE I.

CAlCulations of TLMd PARAMETERS FOR VARYing WATER LEVEL IN THE TANK

\begin{tabular}{|l|l|l|l|l|}
\hline & $\begin{array}{l}\text { Empty } \\
\text { Water } \\
\text { tank }\end{array}$ & $\begin{array}{l}\text { One-third } \\
\text { level Water }\end{array}$ & $\begin{array}{l}\text { Two-third } \\
\text { level water }\end{array}$ & $\begin{array}{l}\text { Full } \\
\text { water } \\
\text { tank }\end{array}$ \\
\hline Mass ratio & 0 & 0.00330 & 0.0066 & 0.00992 \\
\hline Tuning ratio & 1 & 0.996 & 0.993 & 0.9901 \\
\hline $\begin{array}{l}\text { Optimum } \\
\text { damping ratio }\end{array}$ & 0 & 0.03528 & 0.0499 & 0.0613 \\
\hline $\begin{array}{l}\text { Optimum } \\
\text { stiffness } \\
\text { (KN/m) }\end{array}$ & 0 & 82.72 & 164.371 & 244.94 \\
\hline $\begin{array}{l}\text { Optimum } \\
\text { Damping } \\
\text { (KN-s/m) }\end{array}$ & 0 & 30.74 & 87.09 & 160.26 \\
\hline
\end{tabular}

\section{RESULTS AND DISCUSSIONS}

After analyzing the RCC buildings of ten-storey and fifteen-storey high using both Response Spectrum and Linear Time History Analysis methods with and without TLD's, the results obtained in respect of base shear and maximum storey displacement in two orthogonal directions are tabulated in Tables. The studies are carried-out with water tank empty, one-third full, two-third full and full.

\section{A. Zone-III, ten storey building}

1. L-Shaped buildings of ten-storey high with one water tank, when dampers are introduced, the base shear has slightly increased when tanks carry more water as compared to the tank without dampers. But the maximum displacement reduced by $43 \%$ when dampers are introduced.

2. L-Shaped building of ten-storey high with TWO water tanks, when dampers are introduced, the base shear has slightly increased when tanks are filled as compared to the tanks without dampers, but the maximum displacement was $58 \%$ less when dampers are introduced.

3. L-Shaped building of ten-storey high with THREE water tanks, when dampers are introduced, the base shear has slightly increased when tanks are filled as compared to the tanks without dampers, but the maximum displacement was $63 \%$ less when dampers are introduced.

4. T-Shaped building of ten-storey high with ONE water tank, when dampers are introduced, the base shear has slightly increased when tanks are filled as compared to the tank without dampers, but the maximum displacement was $43 \%$ less when dampers are introduced.
5. T-Shaped building of ten-storey high with TWO water tanks, when dampers are introduced, the base shear has slightly increased when tanks are filled as compared to the tanks without dampers, but the maximum displacement was $55 \%$ less when dampers are introduced.

6. T-Shaped building of ten-storey high with THREE water tanks, when dampers are introduced, the base shear has slightly increased when tanks are filled as compared to the tanks without dampers, but the maximum displacement was $58 \%$ less when dampers are introduced.

7. U-Shaped building of ten-storey high with ONE water tank, when dampers are introduced, the base shear has slightly increased when tanks are filled as compared to the tank without dampers, but the maximum displacement was $24 \%$ less when dampers are introduced.

8. U-Shaped building of ten-storey high with TWO water tanks, when dampers are introduced, the base shear has slightly increased when tanks are filled as compared to the tanks without dampers, but the maximum displacement was $41 \%$ less when dampers are introduced.

9. U-Shaped building of ten-storey high with THREE water tanks, when dampers are introduced, the base shear has increased when tanks are filled as compared to the tanks without dampers, but the maximum displacement was $47 \%$ less when dampers are introduced.

10. Rectangular-Shaped building of ten-storey high with ONE water tank, when dampers are introduced, the base shear has decreased when tanks are filled as compared to the tank without dampers, but the maximum displacement was $18 \%$ less when dampers are introduced.

11. Rectangular-Shaped building of ten-storey high with TWO water tanks, when dampers are introduced, the base shear has decreased when tanks are filled as compared to the tanks without dampers, but the maximum displacement was 34\% less when dampers are introduced.

12. Rectangular-Shaped building of ten-storey high with THREE water tanks, when dampers are introduced, the base shear has slightly decreased when tanks are filled as compared to the tanks without dampers, but the maximum displacement was $42 \%$ less when dampers are introduced.

\section{B. Zone-IV, ten storey building}

13. L-Shaped building of ten-storey high with ONE water tank, when dampers are introduced, the base shear has slightly increased when tanks are filled as compared to the tank without dampers, but the maximum displacement was $42 \%$ less when dampers are introduced.

14. L-Shaped building of ten-storey high with TWO water tanks, when dampers are introduced, the base shear has slightly increased when tanks are filled as compared to the tanks without dampers, but the maximum displacement was $58 \%$ less when dampers are introduced.

15. L-Shaped building of ten-storey high with THREE water tanks, when dampers are introduced, the base shear has slightly increased when tanks are filled as compared to the tanks without dampers, but the maximum displacement was $63 \%$ less when dampers are introduced.

16. T-Shaped building of ten-storey high with ONE water tank, when dampers are introduced, the base shear has 
slightly increased when tanks are filled as compared to the tank without dampers, but the maximum displacement was $44 \%$ less when dampers are introduced.

17. T-Shaped building of ten-storey high with TWO water tanks, when dampers are introduced, the base shear has slightly increased when tanks are filled as compared to the tanks without dampers, but the maximum displacement was $55 \%$ less when dampers are introduced.

18. T-Shaped building of ten-storey high with THREE water tanks, when dampers are introduced, the base shear has increased when tanks are filled as compared to the tanks without dampers, but the maximum displacement was $58 \%$ less when dampers are introduced.

19. U-Shaped building of ten-storey high with ONE water tank, when dampers are introduced, the base shear has slightly increased when tanks are filled as compared to the tank without dampers, but the maximum displacement was $24 \%$ less when dampers are introduced.

20. U-Shaped building of ten-storey high with TWO water tanks, when dampers are introduced, the base shear has slightly increased when tanks are filled as compared to the tanks without dampers, but the maximum displacement was $41 \%$ less when dampers are introduced.

21. U-Shaped building of ten-storey high with THREE water tanks, when dampers are introduced, the base shear has slightly increased when tanks are filled as compared to the tanks without dampers, but the maximum displacement was $47 \%$ less when dampers are introduced.

22. Rectangular-Shaped building of ten-storey high with ONE water tank, when dampers are introduced, the base shear has decreased when tanks are filled as compared to the tank without dampers, but the maximum displacement was $18 \%$ less when dampers are introduced.

23. Rectangular-Shaped building of ten-storey high with TWO water tanks, when dampers are introduced, the base shear has decreased when tanks are filled as compared to the tanks without dampers, but the maximum displacement was 34\% less when dampers are introduced.

24. Rectangular-Shaped building of ten-storey high with THREE water tanks, when dampers are introduced, the base shear has slightly decreased when tanks are filled as compared to the tanks without dampers, but the maximum displacement was $42 \%$ less, when dampers are used.

\section{Zone-III, fifteen storey building}

1. L-Shaped building of fifteen storey high with ONE water tank, when dampers are introduced, the base shear has slightly decreased when tanks are filled as compared to the tank without dampers, but the maximum displacement was $49 \%$ less when dampers are introduced.

2. L-Shaped building of fifteen-storey high with TWO water tanks, when dampers are introduced, the base shear has slightly increased when tanks are filled as compared to the tanks without dampers, but the maximum displacement was $63 \%$ less when dampers are introduced.

3. L-Shaped building of fifteen storey high with THREE water tanks, when dampers are introduced, the base shear has slightly increased when tanks are filled as compared to the tanks without dampers, but the maximum displacement was $68 \%$ less when dampers are introduced.
4. T-Shaped building of fifteen-storey high with ONE water tank, when dampers are introduced, the base shear has slightly decreased when tanks are filled as compared to the tank without dampers, but the maximum displacement was $50 \%$ less when dampers are introduced.

5. T-Shaped building of fifteen storey high with TWO water tanks, when dampers are introduced, the base shear has slightly decreased when tanks are filled as compared to the tanks without dampers, but the maximum displacement was $61 \%$ less when dampers are introduced.

6. T-Shaped building of fifteen storey high with THREE water tanks, when dampers are introduced, the base shear has slightly increased when tanks are filled as compared to the tanks without dampers, but the maximum displacement was $64 \%$ less when dampers are introduced.

7. U-Shaped building of fifteen storey high with ONE water tank, when dampers are introduced, the base shear has slightly decreased when tanks are filled as compared to the tank without dampers, but the maximum displacement was 30\% less when dampers are introduced.

8. U-Shaped building of fifteen storey high with TWO water tanks, when dampers are introduced, the base shear has slightly decreased when tanks are filled as compared to the tanks without dampers, but the maximum displacement was $49 \%$ less when dampers are introduced.

9. U-Shaped building of fifteen storey high with THREE water tanks, when dampers are introduced, the base shear has decreases when tanks are filled as compared to the tanks without dampers, but the maximum displacement was $55 \%$ less when dampers are introduced.

10. Rectangular-Shaped building of fifteen storey high with ONE water tank, when dampers are introduced, the base shear has decreased when tanks are filled as compared to the tank without dampers, but the maximum displacement was $29 \%$ less when dampers are introduced.

11. Rectangular-Shaped building of fifteen storey high with TWO water tanks, when dampers are introduced, the base shear has slightly decreased when tanks are filled as compared to the tanks without dampers, but the maximum displacement was $43 \%$ less when dampers are introduced.

12. Rectangular-Shaped building of fifteen storey high with THREE water tanks, when dampers are introduced, the base shear has slightly increased when tanks are filled as compared to the tanks without dampers, but the maximum displacement was $48 \%$ less when dampers are introduced.

\section{Zone-IV, fifteen storey building}

13. L-Shaped building of fifteen storey high with ONE water tank, when dampers are introduced, the base shear has slightly reduced when tanks are filled as compared to the tank without dampers, but the maximum displacement was $49 \%$ less when dampers are introduced.

14. L-Shaped building of fifteen storey high with TWO water tanks, when dampers are introduced, the base shear has slightly increased when tanks are filled as compared to the tanks without dampers, but the maximum displacement was $63 \%$ less when dampers are introduced.

15. L-Shaped building of fifteen storey high with THREE water tanks, when dampers are introduced, the base shear has slightly increased when tanks are filled as compared 
to the tanks without dampers, but the maximum displacement was $68 \%$ less when dampers are introduced.

16. T-Shaped building of fifteen storey high with ONE water tank, when dampers are introduced, the base shear has slightly reduced when tanks are filled as compared to the tank without dampers, but the maximum displacement was $50 \%$ less when dampers are introduced.

17. T-Shaped building of fifteen storey high with TWO water tanks, when dampers are introduced, the base shear has slightly reduced when tanks are filled as compared to the tanks without dampers, but the maximum displacement was $61 \%$ less when dampers are introduced.

18. T-Shaped building of fifteen storey high with THREE water tanks, when dampers are introduced, the base shear has slightly increased when tanks are filled as compared to the tanks without dampers, but the maximum displacement was $64 \%$ less when dampers are introduced.

19. U-Shaped building of fifteen storey high with ONE water tank, when dampers are introduced, the base shear has slightly reduced when tanks are filled as compared to the tank without dampers, but the maximum displacement was 30\% less when dampers are introduced.

20. U-Shaped building of fifteen storey high with TWO water tanks, when dampers are introduced, the base shear has slightly reduced when tanks are filled as compared to the tanks without dampers, but the maximum displacement was $49 \%$ less when dampers are introduced.

21. U-Shaped building of fifteen storey high with THREE water tanks, when dampers are introduced, the base shear has slightly reduced when tanks are filled as compared to the tanks without dampers, but the maximum displacement was 55\% less when dampers are introduced.

22. Rectangular-Shaped building of fifteen storey high with ONE water tank, when dampers are introduced, the base shear has slightly reduced when tanks are filled as compared to the tank without dampers, but the maximum displacement was $29 \%$ less when dampers are introduced.

23. Rectangular-Shaped building of fifteen storey high with TWO water tanks, when dampers are introduced, the base shear has slightly reduced when tanks are filled as compared to the tanks without dampers, but the maximum displacement was $43 \%$ less when dampers are introduced.

24. Rectangular-Shaped building of fifteen storey high with THREE water tanks, when dampers are introduced, the base shear has slightly increased when tanks are filled as compared to the tanks without dampers, but the maximum displacement was 51\% less when dampers are introduced.

\section{CONCLUSIONS}

In the present work, the dynamic analysis using ETABS package is performed on 10-storey and 15-Storey RCC buildings of different plan shapes in zone-3 and zone-4, with and without tuned liquid dampers. The results pertaining to base shear and maximum floor displacements are tabulated. With the values of the base shear and maximum lateral displacements available from tables, in chapter-5, the results and discussions are documented. Finally, based on the results and discussions, following conclusions are drawn.
1. Introduction TLD modelling of water tanks have invariably reduced the magnitudes of base shear and maximum lateral displacements to an extent of twenty percent.

2. Increasing water levels in the tanks, with either single or multiple TLD's have resulted in the marginal increase in base shear but substantial decrease the maximum lateral displacements for RCC buildings with L shaped plans.

3. A similar behaviour is noticed for buildings with rectangular, T shaped and U-shaped plans as well.

4. Even though the magnitudes of base shear and maximum lateral displacement increase are higher for zone-4 in relation to zone-3, the magnitudes of base shear and maximum lateral displacements have exhibited a similar trend.

5. The structural design of high raised RCC buildings with multiple water tanks is most economical when the water tanks are modelled as TLDs. For design purpose, the maximum values of base shear and maximum lateral displacements shall be considered based on the quantum of water in tanks.

6. Even though, the sizing of water tank is decided based on the water requirements of a building, they are divided into multiple numbers to cause minimum dynamic disturbance to the building, in the event of seismic activity.

\section{A. Scope for future work}

As of now, a large amount of information is available regarding the base shear and the maximum lateral displacement for RCC buildings of different heights, different seismic zones, and different shapes of plans both with and without TLDs. This large data set may be used to train a neural net using back propagation paradigm. The input layer of the neural net would contain the shape of the building, numbers of stories, seismic zone coefficient, and number of TLDs, the relative fullness of tanks, Mass/Damping/Stiffness information of TLDs and their location with respect to mass center of the building in plan. The outputs of the net shall be the base shear and maximum lateral displacement. Such a trained neural net would recommend optimum configuration of numbers of TLD's, their locations in building plan and their capacities.

\section{REFERENCES}

[1] Chidige Anil Kumar, E Arunakanthi "A Seismic Study on Effect of Water Tank modelled as Tuned Mass Damper", International Journal of Innovation Research in Science, Engineering and Technology (2017).

[2] Dorothy Reed, Jinkyu Yu, z Harry Yes, Sigurdur Gardarsson "Investigation of Tuned Liquid Dampers under Large Amplitude Excitation", American Society of Civil Engineers (1998).

[3] M. J. Tait, N. Isyumov, A. EI Damatty "Performance of Tuned Liquid Dampers", American Society of Civil Engineers (2008).

[4] Mudabbir Imron, Dr. B. K. Raghu prasad "Seismic Response of Tail Structure Using Tuned Mass Dampers", International Journal of Research in Engineering and Applied Science (2017).

[5] A. Lucchini, R. Greco, G. C. Marano and G. Monti "Robust Design of Tuned Mass Damper Systems for Seismic Protection 
of Multi-Storey Buildings", American Society of Civil Engineers (2014).

[6] Emiliano Matta, "Effectiveness of Tuned Mass Dampers against Ground Motion Pulses", American Society of Civil Engineers (2013).

[7] Manjusha M, Dr. Vra Saathappan "Analytical Investigation of Water Tank as Tuned Mass Damper Using Etabs", International Research Journal of Engineering and Technology (2017).

[8] Khemraj S. Deore, Dr. Rajasekhar S. Talikoti, Kanhaiya K. Tolani "Vibration Analysis of structure using Tuned Mass Damper", International Research Journal Engineering and Technology (2017).

[9] Ahmad Abdelraheem Fraghaly, Mahmoud Salem Ahmed "Optimum Design of Tuned Mass Damper System for Tall buildings", International Scholarly Research Network (2012).

[10] S. M. Zahari, A. Ghannadi-Asl "Seismic Performance of Tuned Mass Dampers in Improving the Response of MRF Buildings", Scientia Iranica (2008).

[11] Ashish A. Mohite, G.R. Patil "Earthquake Analysis of Tall Building with Tuned Mass Damper", ISOR (2015).

[12] Saurabh Chalke, P. V. Muley "Vibration Control of Framed Structure Using Tuned Mass Damper" International Journal of Engineering Development and Research (2017).
[13] Dargush and Soong "Passive energy dissipation system for structural for design and retrofit.

[14] Fahim Sadek, Bijan Mohraz, Andrew W. Taylor and Riley M. Chung "A Method of Estimating the Parameters of Tuned Mass Dampers for Seismic Applications" (1997).

[15] Den Hartog "A Book on Mechanical Vibrations".

[16] A Shruthi, Dr. N. Murali Krishna "Role of Liquid Tuned Mass Dampers in Improving Torsional Competence of Asymmetric Buildings" CVR Journal of Science and Technology (2019). 